\title{
Epigenetic Modifications: Therapeutic Potential in Cancer
}

\author{
Manisha Sachan* and Manpreet Kaur \\ Motilal Nehru National Institute of Technology; Allahabad - Biotechnology, Allahabad, Uttar Pradesh - \\ India
}

\begin{abstract}
Epigenetic modifications and alterations in chromatin structure and function contribute to the cumulative changes observed as normal cells undergo malignant transformation. These modifications and enzymes (DNA methyltransferases, histone deacetylases, histone methyltransferases, and demethylases) related to them have been deeply studied to develop new drugs, epigenome-targeted therapies and new diagnostic tools. Epigenetic modifiers aim to restore normal epigenetic modification patterns through the inhibition of epigenetic modifier enzymes. Four of them (azacitidine, decitabine, vorinostat and romidepsin) are approved by the U.S. Food and Drug Administration. This article provides an overview about the known functional roles of epigenetic enzymes in cancer development.
\end{abstract}

Key words: HDAC inhibitors; Cancer epigenetics; Histone modification

\section{INTRODUCTION}

Conrad Waddington coined the term 'epigenetics' as to explain why genetic variations sometimes did not lead to phenotypic variations and how genes might interact with their environment to yield a phenotype (Waddington 1942). The term currently, however, refers specifically to the study of mitotically and/or meiotically heritable changes in gene expression that occur without changes in the DNA sequence (Bird 2002). Two of the most studied epigenetic phenomena are DNA methylation and histone tail modifications.

The development of cancer is controlled by both genetic and epigenetic changes. Accumulation of genetic defects such as translocations, mutations, deletions and amplification are the major cause of transformation of normal cell to cancerous cell. On the other hand, epigenetics encompasses the wide range of heritable changes in gene expression that do not result from an alteration in the DNA sequence itself. Chromatin is a highly dynamic structure that must be modified to allow the binding of transcriptional machinery when gene expression is required, to allow DNA repair mechanisms, or for DNA replication. DNA methylation and histone modification, as epigenetic mechanisms, regulate the access of the transcription machinery to their target genes, modulating transitions from the condensed heterochromatin to relaxed euchromatin and vice versa. These mechanisms work synergistically to regulate the chromatin structure and to achieve the required degree of gene expression, required for normal physiological cell functions and a wide variety of biological processes (Siedel et al. 2012). Studies during the past decade have shown that epigenetics play a key role in carcinogenesis and tumour progression. Epigenetic modifications are reversible, and therefore, are being increasingly studied to find out the biomarkers for the early detection of cancer or to explore novel therapies to treat cancer by reversing these effects. This article will discuss the epigenetic modifications and how

*Author for correspondence: manishas77@rediffmail.com 
these are linked to cancer; give a brief overview of the clinical use of epigenetic drugs, epigenetics as biomarkers and its limitations.

\section{DNA METHYLATION}

DNA methylation takes place at the 5' position of the cytosine ring within $\mathrm{CpG}$ dinucleotides by DNA methyltransferase, which leads to the silencing of genes and noncoding genomic regions. $\mathrm{CpG}$ sites are concentrated either in $\mathrm{CpG}$ islands (short $\mathrm{CpG}$-rich DNA regions) that are located in approximately $60 \%$ of human gene promoters or in large repetitive sequences (for example, centromeres, gene bodies and retrotransposon elements) (Bird 2002b). There are three main DNA methyltransferases (DNMTs) that transfer a methyl group from the methyl donor molecule S-adenosyl-L-methionine to the carbon 5 of the cytosine: DNMT1 (maintenance enzyme), which maintains the existing methylation patterns following DNA replication whereas DNMT3A and DNMT3B (de novo enzymes) target previously unmethylated CpGs. Methylation in the normal cell usually occurs in these repetitive regions that are involved in chromosomal stability, non-coding regions (i.e., enhancer regions and miRNAs), and gene bodies (silencing alternative transcription start sites) whereas the majority of $\mathrm{CpG}$ islands remain unmodified during the development and in differentiated tissues (Suzuki and Bird 2008). 5methylcytosine can be further converted into 5hydroxymethyl-2-deoxycytidine by the TenEleven-Translocation (TET) family enzymes (Tahiliani et al. 2009). The function and significance of 5-hydroxymethylation are still unclear and under investigation.

(a)

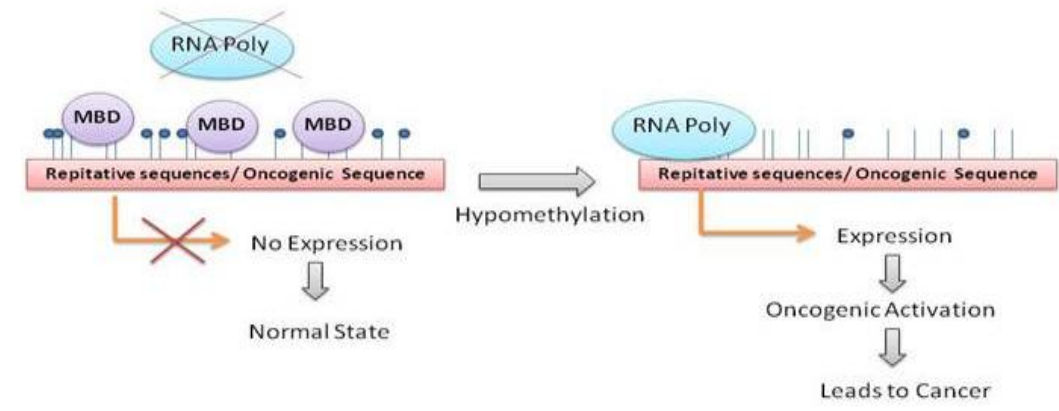

(b)

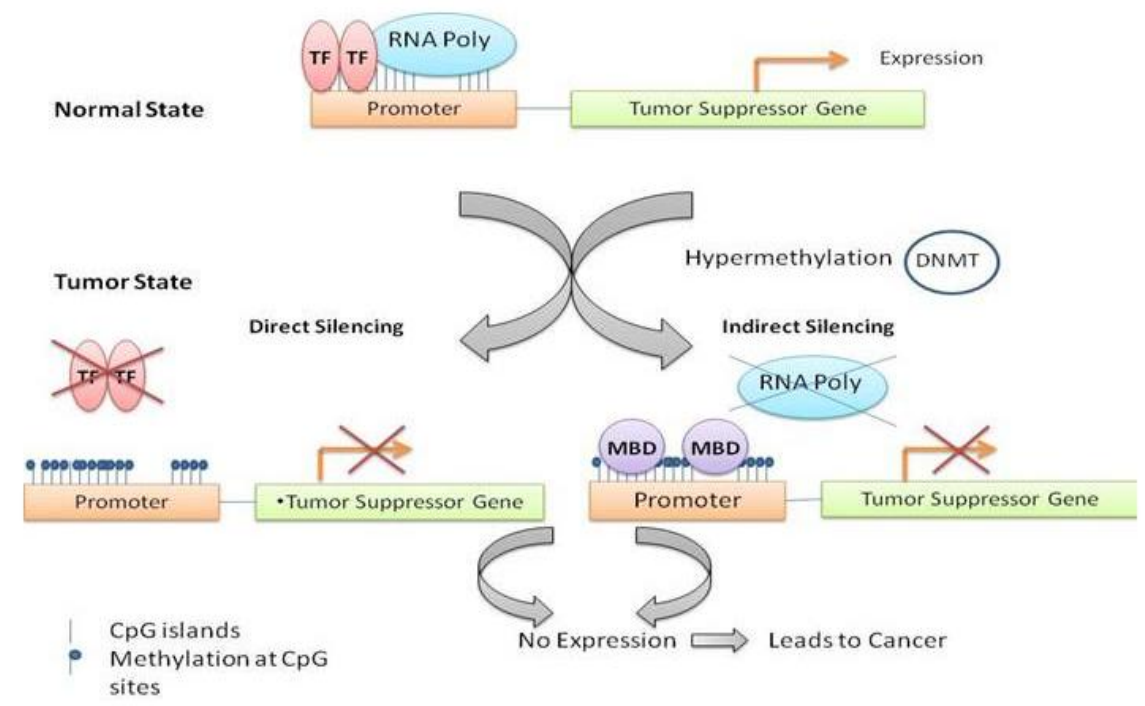

Figure 1 - Methylation pattern in normal and tumor state. Hypo- and hypermethylation in the promoter leads to disease in the cell. (a) Repitative/oncogenic sequences are normally hypermethylated preventing their expression and chromosomal instability. Hypomethylation in these sequences make them transcriptionally active which leads to cancer. (b) $\mathrm{CpG}$ islands at tumor suppressor genes are normally unmethylated. Methylation of these sites by DNMTs suppresses their expression either by Direct Silencing where the TF are not able to bind at promoter region or by Indirect Silencing where MBDs come and bind at the methylated $\mathrm{CpG}$ sites and block the binding of RNA Polymerase.MBD- Methyl binding protein, TF- Transcription factors, DNMT- DNA Methyltransferase. 


\section{HISTONE MODIFICATION}

The mammalian genome is compacted in a hierarchical structure that involves highly conserved basic proteins, known as histones. DNA is wrapped around a core of eight histones to form nucleosomes, which is called the smallest structural unit of chromatin. A nucleosome is composed of an octamer consisting of core histone proteins, i.e., a $\mathrm{H} 3 / \mathrm{H} 4$ tetramer and two $\mathrm{H} 2 \mathrm{~A} / \mathrm{H} 2 \mathrm{~B}$ dimers, and $147 \mathrm{bp}$ of DNA wrapped around it. The basic amino-terminal tails of histones protrude out of the nucleosome and are subject to posttranslational modifications, which include acetylation by histone acetyltransferases (HATs)/deacetyltransferases (HDACs), histone methylation by histone lysine methyltransferases
(HMTs)/ demethylation (HDM), phosporylation, ubiquitylation and sumoylation. These modifications influence how tightly or loosely the chromatin is compacted, and thus plays a regulatory role in gene expression (Annunziato 2008).

In humans, eighteen different HDACs have been identified and divided into two families on the basis of their catalytic mechanism of action and sequence homology. The classical HDAC family consists of proteins with a highly conserved catalytic domain that require a zinc cation for catalytic activity. The HDACs catalyze removal of acetyl groups from lysine residues in the histones. These proteins are divided into five classes as shown in Table 1 (Ruijter et al. 2003).

Table 1 - Classification table for HDAC.

\begin{tabular}{cccc}
\hline Classification & HDACs & Size (aa*) & Subcellular Location \\
\hline Class I & HDAC 1 & 483 & Nucleus \\
& HDAC 2 & 488 & Nucleus \\
& HDAC 3 & 423 & Nucleus \\
& HDAC 8 & 377 & Nucleus/Cytoplasm \\
& HDAC 4 & 1084 & Nucleus/Cytoplasm \\
& HDAC 5 & 1122 & Nucleus/Cytoplasm \\
& HDAC 7 & 855 & Nucleus/Cytoplasm \\
\hline Class IIa & HDAC 9 & 1011 & mainly cytoplasm \\
& HDAC 6 & 1215 & mainly cytoplasm \\
\hline Class IIb & HDAC 10 & 669 & nucleus \\
& SIRT 1 & 747 & mainly cytoplasm \\
& SIRT 2 & 373 & mitochondria \\
& SIRT 3 & 399 & mitochondria \\
& SIRT 4 & 314 & nucleus \\
& SIRT 5 & 310 & nucleolus \\
\hline Class IV & SIRT 6 & 355 & Nucleus/Cytoplasm \\
\hline
\end{tabular}

*aa= amino acids

\section{EPIGENETIC MODIFICATIONS IN CANCER}

Epigenetic changes are increasingly recognized as a major characteristic of human cancers. This was first shown by the biochemical analyses of tumor DNA, which revealed a $20 \%$ reduction in global DNA methylation levels (Feinberg et al. 1988). Later studies have shown that the most recognized epigenetic disruption in human tumors is the $\mathrm{CpG}$ island promoter hypermethylation- associated silencing of tumor suppressor genes, such as genes involved in DNA repair (BRCA1, MGMT and $M L H 1)$, signal transduction (RASSF1A), cell cycle regulation (p16INK4a), apoptosis (DAPK and TMS1) and angiogenesis (THBS1) (Esteller 2002; Esteller 2007; Esteller 2008). Aberrant DNA hypomethylation can also account for the activation of some protooncogenes and lead to the loss of imprinting, such as IGF2 gene (encoding insulin-like growth factor-2) in Wilms's tumor (Ogawa et al. 1993), HOX-11 in leukemia (Watt et al. 2000).

DNMT3A deletion may promote cancer progression, whereas DNMT3B deletion may inhibit oncogenesis by liberating previously silenced tumor-suppressor genes. DNMTs cooperate to silence genes and promote cell survival in at least some human cancers and overexpression of $D N M T 1 / 3 A / 3 B$ is common in the lung, prostate and breast cancer and in many other malignancies (Ganesan et al. 2009). Patients 
with DNMT3A-mutated AML have an inferior survival when treated with standard-dose anthracycline induction therapy (Sehgal et al. 2015).

Disruption of normal patterns of covalent histone modifications is another hallmark of cancer. One of the most characteristic examples is the global reduction of the trimethylation of $\mathrm{H} 4 \mathrm{~K} 20$ (H4K20me3) and acetylation of H4K16 (H4K16Ac), along with DNA hypomethylation at repetitive sequences in many primary tumors (Fraga et al. 2005). In cancer, histone modifications can be deregulated by overexpression, mutations and/or chromosomal translocations of any of the histone acetylation/deacetyaltion (HAT/HDAC) and methylation/demethylation (HMT/HDM or sirtuins) enzymes (Seligson et al. 2005). Histone lysine methyltransferases (SETD1 and 2) are found as novel tumor suppressors. Downregulation of SETD2 promotes both initiation and progression in leukemia (Zhu et al. 2014), whereas hSETD1 A controls tumor metastasis by activating $M M P$ expression (Salz et al. 2014). An upregulation of EZH2 (Enhancer of Zeste 2, a histone methyltransferase) has been observed in a wide variety of tumors, such as prostate cancer, lymphomas, colorectal and gastric cancer, and bladder and breast cancer. It was suggested that EZH2 could be an oncogene (Liang et al. 2013). Particular gene involved in tumor suppression and cell growth regulation that are known to be silenced through HDAC mediated epigenetic mechanisms include $p 21, p 27, p 16, p 19$, among many others (Atadja 2011).

Considering the importance of DNA methylation

and histone acetylation in the initiation and progression of human cancer, these mechanisms are identified as novel therapeutic targets. By inducing demethylation of DNA and histone acetylation, these compounds can reverse the epigenetic silencing of tumor suppressor genes, resulting in reactivation of these genes in tumor cells and restoration of crucial cellular pathways.

\section{CANCER EPIGENETICS THERAPY}

DNA Methylation Inhibitors: Demethylating agents are relatively new class of anticancer drugs that alter DNA methylation through DNMT inhibition. These drugs can be divided into two major structural groups - nucleoside and nonnucleoside analogs (Table 2).
Table 2 - Classification of DNMT inhibitors.

\begin{tabular}{cc}
\hline Nucleoside & Non-Nucleoside Analogues \\
Analogues & \\
\hline Azacytidine & Natural Compunds: Flavonoids \\
Decitabine & Psammaplin A \\
NPEOC-DAC & Curcumin \\
SGI-110 & Synthetic Compunds: Procaine \\
CP-4200 & (-)-Epigallocatechin-3-galate \\
5.6-Dihydro- & Mythramycin A \\
azacytidine & \\
5-Fluoro-2- & Nanomycin A \\
deoxycytidine & RG-108 \\
Zebularine & SGI-1027 \\
& NSC-14778 \\
& NSC-106084 \\
\end{tabular}

Nucleoside analogues have a modified cytosine ring that is attached to either a ribose or deoxyribose moiety. The most extensively studied nucleoside analogs, 5-azacytidine (VidazaR) and 5-aza-2'-deoxycytidine or decitabine (DacogenR), have been approved by the FDA and EMA for the treatment of myelodysplastic syndrome (MDS). They have also shown promising results in the patients with acute myeloid leukemia (AML) and chronic myelomonocytic leukemia (CMML) in several clinical studies. 5-azacytidine and 5-aza2'-deoxycytidine (decitabine) are two cytidine analogs in which carbon atom in position 5 is replaced by a nitrogen atom and linked to a ribose or a deoxyribose, respectively (Portela and Esteller 2010). It has been reported that 5-azacytidine and decitabine can induce apoptosis in the neoplastic mast cells through re-expression of Fas receptor (Ghoshal et al. 2005). It has also been shown that 5 -azacytidine treatment leads to apoptosis of both myeloid precursor PC-MDS cells and leukemia K562 cells, mainly through the induction of Bak mRNA expression (Ghanim et al. 2012). Dihydro5-azacytidine (DHAC) is hydrolytically more stable (Beisler et al. 1977) and less cytotoxic (Presant et al. 1981) than 5-Aza-CR, and has been proved to be an inhibitor of DNA methylation in human lymphoid and leukaemia cell lines, as well as in tumour-bearing mice (Antonsson et al 1987; Powell and Avramis 1988; Kees and Avramis 1995). Human prostate cancer invasion could be suppressed by 5-Aza-2'-deoxycytidine, which can inhibit the TGF- $\beta$ induced DNMT by demethylation of the $T G F-\beta$ receptors gene promoters (Zang et al. 2014). 5-fluoro-2'deoxycytidine (5-F-CdR) is another cytosine 
analogue with antitumour and demethylating properties and is currently undergoing Phase I studies. It has been shown that FCdR inhibits the colon cancer cell line at G2/M stage by activating the DNA damage response pathway (Zhao et al. 2012). Zebularine or 1- $\beta$-d-ribofuranosyl-2(1H)pyrimidinone has been shown to be less toxic than the 5-aza-nucleosides in the cultured cells. However, zebularine's near millimolar dose requirement, mutagenicity, and limited bioavailability in rodents and primates (Holleran et al. 2005) prevent it to directly enter into the clinical phase. Future work should focus on the development of a zebularine pro-drug that overcome these limitations. Zebrularine has been reported to inhibit tumorigenesis in various cancer cell lines, such as colorectal cancer, breast cancer, hepatic carcinoma, pancreatic adenocarcinoma (Jonathan et al. 2004; Billam et al. 2010; Kazuaki et al. 2013).

Non-nucleoside analogues are also being studied. Procainamide and its ester analog procaine have shown DNMT inhibitory effects in various cancers. Other synthetic compounds, such as RG108 and SGI-1027 inhibit DNMT1, 3A and 3B, and thus show the antitumor activities. Recently, RG108 has been shown as an effective tumor growth suppressor in most prostate cancer cell lines. This effect is due to the reversion of aberrant DNA methylation that affects the epigenetically silenced cancer related-genes in prostate cancer (Graca et al. 2014). MG98 is an antisense oligonucleotide that specifically inhibits DNMT1 mRNA and that has been tested in the clinical trials (Gros et al. 2012). Some patents have also shown new progress in the area of non-nucleoside DNMT inhibitors like (L)-S-adenosyl-Lhomocysteine (L-SAH) and its derivatives have been designed and synthesized as inhibitors of human DNMT enzymes (Isakovic et al. 2009). PRIMA-1 (p53 reactivation and induction of massive apoptosis) induced global DNA demethylation in p53 mutant cells by inhibiting the expression of DNA methyltransferase DNMT 1, $3 a$ and $3 b$, which dramatically increased the expression of the ten-eleven translocation (TET) family (Wei et al. 2014), particularly TET1. As none of the described non-nucleoside inhibitors have entered clinical development yet, there is still a long way to go before the identification of novel, selective, non-nucleoside DNMT inhibitors.

Several natural compounds have also been shown to exert the DNA demethylating effects, such as some flavonoids, psammaplin A, curcumin. One of the most studied flavonoids with DNMT inhibitory activity is epigallocatechin- 3-O-gallate (EGCG), the main polyphenol of green tea with established preventive antitumor properties. EGCG treatment decreased global DNA methylation levels in A431 cells in a dose-dependent manner. It also lowers down the levels of 5-methylcytosine, DNA methyltransferase (DNMT) activity, messenger RNA (mRNA) and DNMT1, DNMT3a and DNMT3b protein levels (Nandakumar et al. 2011).

\section{Histone Modification Inhibitors}

Cancer cells are characterized by the dysregulation of histone methyltransferases/ demethylases and overexpression of histone deacetylases (HDACs). HDAC inhibitors includes both natural and synthetic compounds that can be divided into four chemically distinct classes based on their structure: short-chain fatty acids (e.g., sodium $n$ butyrate $(\mathrm{NaB})$, phenylacetate, phenylbutyrate, valproate); hydroxamic acids (e.g., trichostatin A, vorinostat (SAHA), panobinostat, belinostat); cyclicpeptides (romidepsin (formerly FK-228)) and benzamide derivatives (MS-275 (or entinostat), MGCD-0103). All the HDAC inhibitors have a metal-binding domain that block substrate-Zn chelation at the HDAC active sites (Keppler and Archer 2008). The main anticancer effects of HDAC inhibitors are cell cycle arrest at G1 or G2-M stage and induction of differentiation and apoptosis. They can also inhibit angiogenesis and metastasis, as well as enhance the sensitivity to chemotherapy (Marchion and Münster 2007).

Sodium butyrate was the first HDACi reported to induce the acetylation (Riggs et al. 1977); later on trichostatin (TSA) and valproic acid (a widely used antiepileptic) were identified. Several HDACi are being tested in phase II-III trials as shown in Table 3 (Tan et al. 2010). Vorinostat and romidepsin are the first FDA and EMEA approved agents for the treatment of progressive or recurrent cutaneous $\mathrm{T}$ cell lymphoma (CTCL) (Raffoux et al. 2010), but convincing clinical evidence of these agents against other cancer types is still lacking (Witta et al. 2012). In the non-small-cell lung cancer, a number of HDACi such as Pivanex, entinostat, vorinostat and CI-994 are in early phases of clinical development (Gridelli et al. 2008). However, it appears that HDACi may need rational combinations to counterbalance the inherent potential of these compounds to reactivate 
the tumor-progression genes. Histone acetyltransfersae PCAF enhances Akt1 acetylation, which helps in proliferation of human

glioblastoma, suggesting a novel target for clinical application (Zhang et al. 2014).

$\underline{\text { Table } 3 \text { - List of HDACs in clinical trials. }}$

\begin{tabular}{cccc}
\hline Group & Example & Target & Current Status \\
\hline $\begin{array}{c}\text { Short Chain Fatty } \\
\text { Acid }\end{array}$ & Valproic acid (VPA) & HDAC class I, IIa & phase II CT \\
& Phenyl butyrate & HDAC class I, IIa & phase II CT \\
phase II CT
\end{tabular}

HAT p300 inhibitor C646-induced growth inhibition on AE (AML1-ETO fusion protein) positive AML cells is associated with the reduced global histone $\mathrm{H} 3$ acetylation and declined $c$ kit and $b c l-2$ levels, which makes C646 a potential candidate for treating the AE-positive AML (Gao et al. 2013). Aberrant JAK/STAT signaling is involved in the oncogenesis of several cancers. Trichostatin A (histone deacetylase inhibitor) suppresses JAK2/STAT3 signaling via inducing the promoter-associated histone acetylation of SOCS1and SOCS3 in human colorectal cancer cells, and thus helps in preventing cancer (Xiong et al. 2012). Other compounds such as givinostat (ITF2357) have been shown to selectively target cells harboring the JAK2 V617F mutation (Guerini et al. 2008). Panobinostat (LBH589) has shown its positive results in Hodgkin's lymphoma patients, which relapsed or was refractory to autologous transplantation (Younes et al. 2012) but showed limited activity in myelodysplastic syndrome (MDS) (Dimicoli et al. 2012). However, in solid tumors its results as monotherapy or in combination with other agents were rather disappointing (Strickler et al. 2012; Wang et al. 2012). Second generation $\mathrm{HDACi}$, for example, ACY-1215 are more selective and have recently entered into clinical trials (Santo et al. 2012). It would be really interesting to see the efficacy and safety profile of such compounds.
Sirtuins (SIRT 1-7) in mammals are a family of NAD+-dependent enzymes, which catalyze protein mono-ADP-ribosylation or deacetylation of histone and non-histone proteins (Finkel et al. 2009). Sirtuins are an emerging class of enzymes for cancer treatment, although they act as both tumor suppressors and tumor promoters depending upon the SIRT protein and cancer type. For instance, SIRT 1 exert antitumor activity by deacetylating $\beta$-catenin, and thus suppress the transcription activation and induce cell proliferation, whereas SIRT 3 contribute for the survival of human melanoma cells in vitro (George et al. 2014). According to their role, SIRT inhibitors and activators are used for cancer therapy.

Nicotinamide inhibited SIRT 1 and showed anticancer activity in many different cancers, such as B-cell CLL (Audrito et al. 2011) but it had low therapeutic potential (Bruzzone et al. 2013). The anticancer activity of suramin has been studied in clinical trials. It is widely used in combination with cytotoxic agents against prostate, hepatocellular carcinoma and breast cancer cells (Borges et al. 2014; Fei et al. 2014). Resveratrol arrest G1 phase, and thus reduces the proliferation of gastric cells (Yang et al. 2013). Lamin A (a major nuclear matrix protein) directly binds with and activates SIRT1. Resveratrol activates SIRT1 by increasing its binding with lamin $\mathrm{A}$, thus aiding 
in the nuclear matrix (NM) localization of SIRT1 (Ghosh et al. 2013).

Chaetocin, 3-Deazaneplanocin A (DZNep) and BIX-01294 are the most commonly and widely used HMT inhibitors. DZNep depletes the cellular levels of PRC2 components $(E Z H 2, E E D$ and $S U Z 12$ ), and consequently reduces methylation at various histone sites. It reduces the $\mathrm{H} 3 \mathrm{~K} 27 \mathrm{me} 3$ levels in many cancers and induces apoptosis like in breast cancer, colorectal cancer, lung cancer, chondrosarcomas (Tan et al. 2007; Miranda et al. 2009; Nicolas et al. 2014). DZNep lacks specificity and acts more as a global histone methylation inhibitor, underscoring the need for further development of histone methylation inhibitors. Recently, it has been shown that DZNep, upregulates the expression of TXNIP, which thereby increases ROS production, leading to apoptosis of leukemia cells in AML (Kim et al. 2013). BIX-01294, a diazepine-quinazolineamine derivative transiently reduces the global H3K9me2 levels in several cell lines. BIX induces the intracellular autophagy mediated cell death via EHMT2/G9a dysfunction and intracellular ROS production in breast and colon cancer (Zhou et al. 2011).

Table 4 - Compounds active against Sirtuin.

\begin{tabular}{|c|c|c|c|}
\hline Chemical Class & Componds & Specificity & Action \\
\hline Nicotinamide & $\begin{array}{l}\text { Nicotinamid } \\
\text { e and NAD+ } \\
\text { analogues }\end{array}$ & Sirtuin inhibitor & $\begin{array}{l}\text { inhibit SIRT activity through its } \\
\text { binding to the } C \text { pocket of enzymes. }\end{array}$ \\
\hline Suramin & Suramin & SIRT 1, SIRT 2 inhibitor & $\begin{array}{l}\text { inhibits SIRT activity by binding the } \mathrm{C} \\
\text { pocket, B pocket and part of the } \\
\text { substrate-binding site of the enzyme. }\end{array}$ \\
\hline $\begin{array}{c}\text { Hydroxynaphthaldehyde } \\
\text { derivatives }\end{array}$ & Cambinol & SIRT 1, SIRT 2 inhibitor & $\begin{array}{c}\text { inhibit SIRT activity through its } \\
\text { binding to the C pocket of SIRT } 1 \text { and } \\
2 .\end{array}$ \\
\hline Indoles & EX-527 & $\begin{array}{l}\text { SIRT 1, SIRT 2, SIRT } 3 \\
\text { inhibitor }\end{array}$ & $\begin{array}{l}\text { inhibits SIRT } 1 \text { at } \mathrm{nM} \text { concentrations } \\
\text { and is less active against SIRT } 2 \text { and } \\
\text { SIRT } 3 .\end{array}$ \\
\hline Polyphenol & Resveratrol & SIRT 1 activator & $\begin{array}{l}\text { indirect activation, do not bind to SIRT } \\
1 \text { for its activation. }\end{array}$ \\
\hline
\end{tabular}

Histone methyltransferase and demethylase enzymes are generally more specific than HDACs in that they target fewer residues. However, like HDACs, lysine and arginine methyltransferase enzymes also methylate the proteins other than histones (Geneviève et al. 2012). A new class of oligoamine analogs was found that acted as potent inhibitors specifically for lysine-specific demethylase-1 (LSD1). LSD1 targets H3K4 mono- or dimethylation mark and H3K9 dimethylation (H3K9me2) mark when complexed with the androgen receptor (Metzger et al. 2005); it can also demethylate DNMT1, resulting in destabilization and loss of global maintenance of DNA methylation (Wang et al. 2009). LSD1 inhibited the proliferation of pluripotent cancer cells, including teratocarcinoma, embryonic carcinoma, seminoma or embryonic stem cells that express the stem cell markers Oct4 and Sox2, and colon cancer cells (Wang et al. 2011). Treatment of the colon cancer cells with LSD1 inhibitors (such as SL11144) increases methylation at H3K4, decreases $\mathrm{H} 3 \mathrm{~K} 9$ methylation, and restores the expression of $S F R P 2$, indicating the specificity of LSD1 and its inhibitors (Huang et al. 2009). Its inhibition in neuroblastoma results in decreased proliferation in vitro and reduced xenograft growth (Schulte et al. 2009). The ability of LSD1 to affect both histone and DNA methylation makes it a promising target for epigenetic therapy. Although drugs that target histone methylases and demethylases have considerable potential, more studies are necessary to determine their specificities and stabilities of the changes they make.

Natural molecules are also being tested for their anti-cancer properties. Three naturally occurring HAT inhibitors include curcumin, garcinol and anacardic acid. Curcumin reduces p53 acetylation by specifically inhibiting the EP-300 and 
CREBBP (Balasubramanyam et al. 2004). Garcinol and anacardic acid are both EP300 and KAT2B HAT inhibitors. Antitumor activities of all the three molecules in a wide variety of cancers include interefernce with different cell signaling pathways, like cell cycle (cyclin D1 and cyclin E), apoptosis (activation of caspases and downregulation of antiapoptotic gene products), proliferation (HER-2, EGFR, and $A P-1)$, survival (PI3K/AKT pathway), invasion (MMP-9 and adhesion molecules), angiogenesis (VEGF), metastasis $(C X C R-4)$ and inflammation $(N F-\kappa B$, $T N F, I L-6, I L-1, C O X-2$, and 5-LOX) (Anand et al. 2008; Wu et al. 2011; Ahmad et al. 2012). Green tea polyphenols suppresses class I histone deacetylases, and thus causes cell cycle arrest and apoptosis in prostate cancer (Thakur et al. 2012).

\section{Combination Therapy}

The recognition that a subset of tumor suppressor genes are silenced by a combination of $\mathrm{CpG}$ hypermethylation and histone hypoacetylation has prompted several trials that are in progress. In pretreated metastatic non-small-cell lung cancer patients, the combination of azacytidine and entinostat produced positive clinical responses and four of 19 treated patients had positive therapeutic responses to further agents given immediately after the epigenetic therapy (Juergens et al. 2011). In previously untreated elderly AML and MDS patients, the combination of lenalidomide (an immunomodulator drug) and azacytidine is currently under investigation (NCT01442714). Both the drugs alone (as monotherapy) have already shown efficacy in these cancer patients, so their combination could be very promising (Pollyea et al. 2012). In a Phase I study, decitabine was combined with bortezomib for the treatment of elderly poor risk AML patients and the combination showed good preliminary activity since response rates were very encouraging (Blum et al. 2012).

Relevant chemotherapeutic drugs have also been tested in combination with DNMT, HDAC and SIRT inhibitors. A Phase 2 study combined the thrombopoietin mimetic romiplostim with 5azacytidine in the patients with myelodysplastic syndrome (Kantarjian et al. 2010). The combined treatment such as the treatment with panobinostat with sorafenib demonstrated the highest preclinical efficacy in hepatocellular carcinoma models, providing the rationale for the clinical studies with this novel combination (Lachenmayer et al. 2012).
Another novel combination treatment using the ultraviolet light phototherapy and HDACi appeared as a potent radiosensitiser, allowing the use of lower radiation doses and minimizing the adverse effects of phototherapy (Sung et al. 2014). Combining 5-azacytidine with a DNA-methylating agent, the methyl donor S-adenosyl methionine (SAM), inhibited the global- and gene-specific demethylation induced by 5 -azaCdR, prevented 5azaCdR activation of prometastatic genes UPA and MMP2, resulting in inhibition of cell invasiveness, while retaining its effects on tumor suppressor genes (Chik et al. 2014).

Natural compounds have also been tested in combination with other chemotherapeutic drugs. For example, curcumin in combination with Paclitaxel, Epigallocatechin-3-Gallate, GRP78 etc potentially increases the growth inhibition and apoptosis in the breast, colon and other different cancers (Zhan et al. 2014; Chang et al. 2014; Wang et al. 2014). Thus, epigenetic therapy appears as a promising tool to restore/reverse hormonal sensitivity. A recent clinical study has shown that a combination of vorinostat and tamoxifen is well tolerated and exhibits encouraging activity in reversing the hormone resistance in advanced ER-positive breast cancer (Munster et al. 2011). Another study found that decitabine and histone HDACi such as trichostatin A, scriptaid and entinostat restored the expression of ER mRNA and functional aromatase, along with the enzymatic activity of aromatase, and thus made ER-negative tumors sensitive to endocrine therapy (Raha et al. 2011).

It is also important to determine the epigenome of chemotherapy resistant cancer cells in order to identify the potential silenced genes, before making any epigenetic therapeutic strategies to reverse the resistance. For example, in malignant melanoma, loss of 5-hydroxymethylcytosine (5hmC) has many harmful effects, which leads to downregulation of IDH2 and TET family enzymes. By reintroducing active TET2 or IDH2, melanoma growth is suppressed, which thereby increases tumor-free survival in animal models (Lian et al. 2012).

\section{LIMITATIONS}

Despite the DNMTi's FDA approval and their use in the clinic for certain malignancies, their poor pharmacokinetic properties and short half-life represent a major drawback. A major disadvantage of 5-azacytidine and 5-aza-2'-deoxycytidine is 
their instability in neutral aqueous solution and poor pharmacokinetic profile, although 5,6dihydro-5-azacytidine and 5-fluoro-2'deoxycytidine have demonstrated high toxicity in several preclinical studies. Another example was a phase 1 study, which showed that decitabine caused grade 4 neutropenia in most interleukin-2 inmelanoma and renal cell carcinoma patients (Gollob and Sciambi 2007). Myelosuppression was also the predominant toxicity observed in a study combining decitabine with carboplatin (Appleton et al. 2007). However, in a phase II trial, low-dose decitabine was found to restore the sensitivity to carboplatin in the patients with heavily pretreated ovarian cancer, resulting in a high response rate (RR) (Matei et al. 2012). In both the studies, there was evidence that decitabine induced dose dependent demethylation in marker genes such as MLH1, RASSF1A, HOXA10, and HOXA1.

HDAC inhibitors only target $\sim 10 \%$ of all acetylation sites. These inhibitors target global acetylation sites and are not histones specific. More work is necessary to understand the basis for target specification of the global and isoformspecific HDAC inhibitors. Efforts are being made to find new molecules that can selectively inhibit specific HDACs, and thus avoid the side effects that occur with a global HDAC inhibitor, including cardiac toxicity and deficits in hematopoiesis and memory formation.

Both DNMTis and HDACis show poor results in solid tumors. A major likely reason for the disappointing activity of these agents in solid tumours is their limited incorporation into cells, which are proliferating relatively slowly. Another reason is that, agents (e.g., azacytidine) that cause global hypomethylation, reactivate expression of multiple silenced genes including oncogenes and tumour suppressors in different cell types and in different cancers. For example, the oncogene $N T 5 E$ is overexpressed in aggressive metastatic melanomas, when transcriptionally silenced by methylation in breast cancer and shows more favorable prognosis (Wang et al. 2012). Third and key possible reason of their failure is because of their toxicity. A recent clinical trial showed the severe gastrointestinal toxicity in which combination of paclitaxel, carboplatin and vorinostat was used to treat the advanced-stage ovarian carcinoma, Epithelial Ovarian, Primary Peritoneal, and Fallopian Tube Cancer (Mendivil et al. 2013).

Table 5 - Toxic Effects of DNMT inhibitors and HDAC inhibitors

\begin{tabular}{|c|c|c|}
\hline Inhibitors & & Toxic Effects \\
\hline \multirow[t]{5}{*}{$\begin{array}{l}\text { DNMT } \\
\text { Inhibiotors }\end{array}$} & Azacytidine & $\begin{array}{l}\text { Hematological side-effects, gastrointestinal toxicity, erythema } \\
\text { (Christman 2002) }\end{array}$ \\
\hline & Decitabine & Myelosuppression, gastrointestinal toxicity (Derissen et al. 2013) \\
\hline & NPEOC-DAC & Myelosuppression (Byun et al. 2008) \\
\hline & Mithramycin & $\begin{array}{l}\text { Malaise, Gastrointestinal effects, fever, central nervous system effects, } \\
\text { stomatitis, epistaxis, 'ecchymoses, hemorrhage (Kennedy, 1970) }\end{array}$ \\
\hline & ECEG & $\begin{array}{l}\text { Anxiolytic activity, hypoglycemic activity, hypochromic anaemia, } \\
\text { hepatotoxic effects (Mereles et al. 2011) }\end{array}$ \\
\hline \multirow[t]{6}{*}{ HDAC inhibitors } & Valproic acid & Neurological toxicity (Pilatrino et al. 2005) \\
\hline & $\begin{array}{l}\text { Sodium } \\
\text { phenylbutyrate }\end{array}$ & Neurological toxicity only at high doses (Gore et al. 2002) \\
\hline & $\begin{array}{l}\text { AN-9 (butyric } \\
\text { acid prodrug) }\end{array}$ & $\begin{array}{l}\text { Monotherapy was well tolerated, whereas a combination treatment } \\
\text { with docetaxel resulted in severe toxicity and interruption of the study } \\
\text { (Patnaik et al. 2002) }\end{array}$ \\
\hline & $\begin{array}{l}\text { Suberoylanilide } \\
\text { hydroxamic acid } \\
\text { (hydroxamic acid } \\
\text { derivative) }\end{array}$ & $\begin{array}{l}\text { Mild toxicity, dehydration, fatigue, diarrhoea and anorexia; } \\
\text { thrombocytopaenia and anaemia were the doselimiting toxicities (Kelly } \\
\text { et al. 2003) }\end{array}$ \\
\hline & $\begin{array}{l}\text { FK-228 (cyclic } \\
\text { depsipeptide) }\end{array}$ & $\begin{array}{l}\text { Bone marrow toxicity, reversible cardiac arrhythmia (which seems not } \\
\text { to be clinically relevant), fatigue, nausea and vomiting (Piekerz et al. } \\
\text { 2001) }\end{array}$ \\
\hline & $\begin{array}{c}\text { MS-275 } \\
\text { (benzamide) }\end{array}$ & $\begin{array}{l}\text { Gastrointestinal toxicities were the dose-limiting toxicities; cumulative } \\
\text { bone marrow toxicity was also seen (Ryan et al. 2005) }\end{array}$ \\
\hline
\end{tabular}




\section{FUTURE PROSPECTS AND CONCLUSION}

Future cancer therapies will surely exploit the synergistic effects between the epigenetic drugs or between the epigenetic drugs and other antitumoral agents. Moreover, epigenetic drugs such as HDAC or DNMT inhibitors should synergize with DNA-damaging agents because they may offer improved access to chromatin. In the near future, many interesting combinations between epigenetic drugs and cyclin-dependent kinase inhibitors (CDKi) or proteasome inhibitors or engineered transcriptional factors will also be tested as they are capable of selectively reactivating the epigenetically silenced tumor suppressors.

Epigenetic mechanisms control the development and normal cellular behavior. An important priority is to develop the approaches to design new agents that are capable of targeting specific epigenetic altered/mutated targets, rather than affecting global modifications to lower toxicity and side effects. In an era of an increasingly accurate and personalized medicine/therapy, new epigenetic drugs could be developed even against different isoforms or mutated variants of particular enzymes involved in very specific types of cancer. To use the epigenetic drugs for cancer treatment, it is important to enhance the knowledge about the key issues such as the optimal doses for single and combined therapies to avoid the toxicity, the sequence of delivery in combined therapies and tumoral uptake of therapies. Recent advances in high-throughput technologies such as genomewide sequencing combined with RNA profiling, chromatin immunoprecipitation, bisulfite conversion or different quantitative PCR have generated large amounts of data that can be used to properly understand the epigenetic alterations that are common and specific to various disease states or to identify the epigenetic alterations that are causative and those that are merely correlative.

\section{REFERENCES}

Ahmad A, Sarkar SH, Bitar B, Ali S, Aboukameel A, Sethi S, et al. Garcinol regulates EMT and Wnt signaling pathways in vitro and in vivo, leading to anticancer activity against breast cancer cells. Mol Cancer Ther. 2012; 11: 2193-2201.
Anand P, Sundaram C, Jhurani S, Kunnumakkara AB, Aggarwal BB. Curcumin and cancer: An "oldage" disease with an "age-old" solution. Cancer Lett. 2008; 267: 133-164.

Annunziato, A. DNA packaging: Nucleosomes and chromatin. Nature Education. 2008; 1(1): 26.

Antonsson BE, Avramis VI, Nyce J, Holcenberg JS. Effect of 5-azacytidine and congeners on DNA methylation and expression of deoxycytidine kinase in the human lymphoid cell lines CCRF/CEM/0 and CCRF/CEM/dCk-1. Cancer Res. 1987; 47: 36723678.

Appleton K, Mackay HJ, Judson I, Plumb JA, McCormick C, Strathdee G, et al. Phase I and pharmacodynamic trial of the DNA methyltransferase inhibitor decitabine and carboplatin in solid tumors. $J$ Clin Oncol. 2007; 25(29): 4603-4609.

Atadja PW. HDAC inhibitors and cancer therapy. Prog Drug Res. 2011; 67:175-195.

Audrito V, Vaisitti T, Rossi D, Gottardi D, D'Arena G, Laurenti L, et al. Nicotinamide blocks proliferation and induces apoptosis of chronic lymphocytic leukemia cells through activation of the p53/miR34a/SIRT1 tumor suppressor network. Cancer Res. 2011; 71(13):4473-4483.

BalasubramanyamK, Varier RA, Altaf M, Swaminathan V, Siddappa NB, Ranga U, et al. Curcumin, a novel p300/CREB-binding protein-specific inhibitor of acetyltransferase, represses the acetylation of histone/nonhistone proteins and histone acetyltransferase-dependent chromatin transcription. J Biol Chem. 2004; 279: 51163-51171.

Beisler JA, Abbasi MM, Kelley JA, Driscoll JS. Synthesis and antitumor activity of dihydro-5azacytidine, a hydrolytically stable analogue of 5azacytidine. J Med Chem. 1977; 20: 806-812.

Billam M, Sobolewski MD, Davidson NE. Effects of a novel DNA methyltransferase inhibitor zebularine on human breast cancer cells. Breast Cancer Res Treat. 2010; 120(3):581-592.

Bird A. DNA methylation patterns and epigenetic memory. Genes Dev. 2002; 16: 6-21.

Blum W, Schwind S, Tarighat SS, Geyer S, Eisfeld AK, Whitman S, et al. Clinical and pharmacodynamic activity of bortezomib and decitabine in acute myeloid leukemia. Blood. 2012; 119: 6025-6031.

Borges S, Döppler HR, and Storz P. A combination treatment with DNA methyltransferase inhibitors and suramin decreases invasiveness of breast cancer cells. Breast Cancer Res Treat. 2014; 144(1): 79-91.

Bruzzone S, Parenti MD, Grozio A, Ballestrero A, Bauer I, Del Rio A, et al. Rejuvenating sirtuins: the rise of a new family of cancer drug targets. Curr Pharm Des. 2013; 19(4):614-623. 
Byun HM, Choi SH, Laird PW, Trinh B, Siddiqui MA, Marquez VE, et al. 2'-Deoxy-N4-[2-(4-nitrophenyl) ethoxycarbonyl]-5-azacytidine: a novel inhibitor of DNA methyltransferase that requires activation by human carboxylesterase 1. Cancer Letters. 2008; 266(2): 238-248.

Chang YJ, Huang CY, Hung CS, Chen WY, Wei PL. GRP78 mediates the therapeutic efficacy of curcumin on colon cancer. Tumor Biology. 2014; 1-9.

Cheng JC, Yoo CB, Weisenberger DJ, Chuang J, Wozniak C, Liang G, et al. Preferential response of cancer cells to zebularine. Cancer Cell. 2004; 6: 151158.

Chik F, Machnes Z, Szyf M. Synergistic anti-breast cancer effect of a combined treatment with the methyl donor S-adenosyl methionine and the DNA methylation inhibitor 5-aza-2'-deoxycytidine. Carcinogenesis. 2014; 35: 138-144.

Christman JK. 5-Azacytidine and 5-aza-2'deoxycytidine as inhibitors of DNA methylation: mechanistic studies and their implications for cancer therapy. Oncogene. 2002; 21(35): 5483-5495.

Delcuve GP, Khan DH, Davie JR. Roles of histone deacetylases in epigenetic regulation: emerging paradigms from studies with inhibitors. Clin Epigenetics. 2012; 4:1-13.

Dimicoli S, Jabbour E, Borthakur G, Kadia T, Estrov $\mathrm{Z}$, Yang $\mathrm{H}$, et al. Phase II study of the histone deacetylase inhibitor panobinostat (LBH589) in patients with low or intermediate-1 risk myelodysplastic syndrome. Am J Hematol. 2012; 87(1): 127-129.

Derissen EJ, Beijnen JH and Schellens JH. Concise drug review: azacitidine and decitabine. The oncologist. 2013; 18(5): 619-624.

Esteller M. CpG island hypermethylation and tumor suppressor genes: a booming present, a brighter future. Oncogene. 2002; 21(35): 5427-5440.

Esteller M. Epigenetic gene silencing in cancer: the DNA hypermethylome. Hum Mol. Gen. 2007; 16: R50-R59.

Esteller M. Epigenetics in cancer. $N$ Engl J Med. 2008; 358: 1148-1159.

Fei X, Ying Z, Wei J, Tingting P, Chao Z, Hao R et al. Detection of Inhibitory Effects of Suramin and Cisplatin on Hepatocellular Carcinoma Cells Using Surface Plasmon Resonance Imaging. Chem $J$ Chinese U. 2014; 35(1): 30-36.

Feinberg AP, Gehrke CW, Kuo KC, Ehrlich M. Reduced genomic 5-methylcytosine content in human colonic neoplasia. Cancer Res. 1988; 48: 1159-1161.

Fraga, MF, Ballestar E, Villar-Garea A, Boix-Chornet M, Espada J, Schotta G, et al. Loss of acetylation at Lys 16 and trimethylation at Lys20 of histone $\mathrm{H} 4$ is a common hallmark of human cancer. Nat Genet. 2005; 37: 391-400.
Ganesan A, Nolan L, Crabb SJ, Packham G. Epigenetic therapy: histone acetylation, DNA methylation and anti-cancer drug discovery. Curr Cancer Drug Targets. 2009; 9(8): 963-981.

Gao X-n, Lin J, Ning Q-y, Gao L, Yao Y-s, Zhou J, et al. A Histone acetyltransferase p300 inhibitor C646 induces cell cycle arrest and apoptosis selectively in AML1-ETO-positive AML cells. Plos One. 2013; 8(2): e55481.

George J, Nihal M, Singh CK, Zhong W, Ahmad N. The mitochondrial sirtuin SIRT3 promotes survival of human melanoma cells in vitro. Cancer Res. 74, no. 19 Supplement (2014): 3516-3516.

Ghanim V, Herrmann H, Heller G, Peter B, Hadzijusufovic E, Blatt K, et al. 5-azacytidine and decitabine exert proapoptotic effects on neoplastic mast cells: role of FAS-demethylation and FAS reexpression, and synergism with FAS-ligand. Blood. 2012; 119(18): 4242-4252.

Ghosh S, Liu B, Zhou Z. Resveratrol activates SIRT1 in a Lamin A-dependent manner. Cell Cycle. 2013; 12(6): 872-876.

Ghoshal K, Datta J, Majumder S, Bai S, Kutay H, Motiwala T, Jacob ST. 5-Aza-deoxycytidine induces selective degradation of DNA methyltransferase 1 by a proteasomal pathway that requires the KEN box, bromo-adjacent homology domain, and nuclear localization signal. Mol Cell Biol. 2005; 25(11): 4727-4741.

Girard N, Bazille C, Lhuissier E, Benateau H, Llombart-Bosch A, Boumediene $\mathrm{K}$, et al. 3Deazaneplanocin A (DZNep), an inhibitor of the histone methyltransferase EZH2, induces apoptosis and reduces cell migration in chondrosarcoma cells. Plos One. 2014; 9:1-8.

Gollob JA, Sciambi CJ. Decitabine up-regulates S100A2 expression and synergizes with IFN- $\gamma$ to kill uveal melanoma cells. Clin Cancer Res. 2007; 13(17): 5219-5225.

Gore SD, Weng LJ, Figg WD, Zhai S, Donehower RC, Dover G, et al. (2002). Impact of prolonged infusions of the putative differentiating agent sodium phenylbutyrate on myelodysplastic syndromes and acute myeloid leukemia. Clin Cancer Res. 2002; 8(4): 963-970.

Graça I, Sousa EJ, Baptista T, Almeida M, RamalhoCarvalho J, Palmeira C, Henrique R, Jerónimo C. Anti-tumoral effect of the non-nucleoside DNMT inhibitor RG108 in human prostate cancer cells. Curr Pharm Des. 2014; 20(11):1803-1811.

Gridelli C, Rossi A, Maione P. The potential role of histone deacetylase inhibitors in the treatment of nonsmall-cell lung cancer. Crit Rev Oncol Hematol. 2008; 68: 29-36. 
Gros C, Fahy J, Halby L, Dufau I, Erdmann A, Gregoire JM, et al. DNA methylation inhibitors in cancer: recent and future approaches. Biochimie. 2012; 94(11):2280-2296.

Guerini V, Barbui V, Spinelli O, Salvi A, Dellacasa $\mathrm{C}$, Carobbio A et al. The histone deacetylase inhibitor ITF2357 selectively targets cells bearing mutated JAK2V617F. Leukemia. 2008; 22(4): 740-747.

Holleran JL, Parise RA, Joseph E, Eiseman JL, Covey JM, Glaze ER. Plasma pharmacokinetics, oral bioavailability, and interspecies scaling of the DNA methyltransferase inhibitor, zebularine. Clin Cancer Res. 2005; 11: 3862-3868.

Huang Y, Stewart TM, Wu Y, Baylin SB, Marton LJ, Perkins B, et al. Novel oligoamine analogues inhibit lysine-specific demethylase 1 and induce reexpression of epigenetically silenced genes. Clin Cancer Res. 2009; 15: 7217-7228.

Isakovic L, Saavedra OM, Llewellyn DB, Claridge S, Zhan L, Bernstein N, et al. Constrained (1-)-Sadenosyl-1-homocysteine (SAH) analogues as DNA methyltransferase inhibitors. Bioorg Med Chem Lett. 2009; 19(10):2742-2746.

Kantarjian HM, Giles FJ, Greenberg PL, Paquette RL, Wang ES, Gabrilove JL, et al. Phase 2 study of romiplostim in patients with low- or intermediate-risk myelodysplastic syndrome receiving azacitidine therapy. Blood. 2010; 116: 3163-3170.

Kees UR, Avramis VI. Biochemical pharmacology and DNA methylation studies of arabinosyl 5-azacytidine and 5, 6-dihydro-5-azacytidine in two human leukemia cell lines PER-145 and PER-163. Anticancer Drugs. 1995; 6: 303-310.

Kelly WK, Richon VM, O’Connor O, Curley T, MacGregor-Curtelli B, Tong W, et al. (2003). Phase I clinical trial of histone deacetylase inhibitor suberoylanilide hydroxamic acid administered intravenously. Clin Cancer Res. 2003; 9(10):35783588 .

Kennedy B J. Metabolic and toxic effects of mithramycin during tumor therapy. Am J Med. 1970; 49(4): 494-503.

Keppler BR, Archer TK. Chromatin-modifying enzymes as therapeutic targets-Part 1. Expert Opin Ther Targets. 2008; 12: 1301-1312.

Kim Y, Kim YS, Kim DE, Lee JS, Song JH, Kim H, et al. BIX-01294 induces autophagy-associated cell death via EHMT2/G9a dysfunction and intracellular reactive oxygen species production. Autophagy. 2013; 9(12): 2126-2139.

Lachenmayer A, Toffanin S, Cabellos L, Alsinet C, Hoshida Y, Villanueva A, et al. Combination therapy for hepatocellular carcinoma: Additive preclinical efficacy of the HDAC inhibitor panobinostat with sorafenib. J Hepatol. 2012; 56: 1343-1350.

Lian CG, Xu Y, Ceol C, Wu F, Larson A, Dresser K, et al. Loss of 5-hydroxymethylcytosine is an epigenetic hallmark of melanoma. Cell. 2012;150: 1135-1146.
Marchion D, Münster P. Development of histone deacetylase inhibitors for cancer treatment. Expert Rev Anticancer Ther. 2007; 7(4):583-98.

Matei D, Fang F, Shen C, Schilder J, Arnold A, Zeng Y et al. Epigenetic resensitization to platinum in ovarian cancer. Cancer Res. 2012;72: 2197-2205.

Mendivil AA, Micha JP, Brown JV 3rd, Rettenmaier MA, Abaid LN, Lopez KL, et al. Increased Incidence of Severe Gastrointestinal Events With First-Line Paclitaxel, Carboplatin, and Vorinostat Chemotherapy for Advanced-Stage Epithelial Ovarian, Primary Peritoneal, and Fallopian Tube Cancer. Int J Gynecol Cancer. 2013;23: 533-539.

Mereles D and Hunstein W. (2011). Epigallocatechin-3gallate (EGCG) for clinical trials: more pitfalls than promises? Int J Mol Sci. 2011; 12(9), 5592-5603.

Metzger E, Wissmann M, Yin N, Müller JM, Schneider $\mathrm{R}$, Peters $\mathrm{AH}$ et al. LSD1 demethylates repressive histone marks to promote androgen-receptordependent transcription. Nature. 2005; 437: 436-439.

Miranda TB, Cortez CC, Yoo CB, Liang G, Abe M, Kelly TK, et al. DZNep is a global histone methylation inhibitor that reactivates developmental genes not silenced by DNA methylation. Mol Cancer Ther. 2009; 8: 1579-1588.

Munster PN, Thurn KT, Thomas S, Raha P, Lacevic M, Miller A, et al. A phase II study of the histone deacetylase inhibitor vorinostat combined with tamoxifen for the treatment of patients with hormone therapy-resistant breast cancer. $\mathrm{Br} \quad \mathrm{J}$ Cancer. 2011;104: 1828-1835.

Nakamura K, Aizawa K, Nakabayashi K, Kato N, Yamauchi J, Hata K, et al. DNA Methyltransferase Inhibitor Zebularine Inhibits Human Hepatic Carcinoma Cells Proliferation and Induces Apoptosis. Plos One. 2013;8: 1-11.

Nandakumar V, Vaid M, Katiyar SK. (-)Epigallocatechin-3-gallate reactivates silenced tumor suppressor genes, Cip1/p21 and p16INK4a, by reducing DNA methylation and increasing histones acetylation in human skin cancer cells. Carcinogenesis. 2011; 32(4):537-544.

Ogawa O, Eccles MR, Szeto J, McNoe LA, Yun K, Maw MA, Smith PJ, et al. Relaxation of insulin-like growth factor II gene imprinting implicated in Wilms' tumour. Nature. 1993;362: 749-751.

Patnaik A, Rowinsky EK, Villalona MA, Hammond LA, Britten CD, Siu LL, et al. A phase I study of pivaloyloxymethyl butyrate, a prodrug of the differentiating agent butyric acid, in patients with advanced solid malignancies. Clin Cancer Res, 2002; 8(7): 2142-2148.

Piekarz RL, Robey R, Sandor V, Bakke S, Wilson WH, Dahmoush L, et al. Inhibitor of histone deacetylation, depsipeptide (FR901228), in the treatment of peripheral and cutaneous T-cell lymphoma: a case report. Blood. 2001; 98(9):2865-2868. 
Pilatrino C, Cilloni D, Messa E, Morotti A, Giugliano $\mathrm{E}$, Pautasso $\mathrm{M}$, et al. Increase in platelet count in older, poor-risk patients with acute myeloid leukemia or myelodysplastic syndrome treated with valproic acid and all-trans retinoic acid. Cancer. 2005; 104(1): 101-109.

Pollyea DA, Kohrt HE, Gallegos L, Figueroa ME, Abdel-Wahab O, Zhang B, et al. Safety, efficacy and biological predictors of response to sequential azacitidine and lenalidomide for elderly patients with acute myeloid leukemia. Leukemia. 2012;26: 893901.

Portela A, Esteller M. Epigenetic modifications and human disease. Nat Biotechnol. 2010; 28(10): $1057-$ 1068

Powell WC, Avramis VI, Biochemical pharmacology of 5, 6-dihydro-5-azacytidine (DHAC) and DNA hypomethylation in tumor (L1210)-bearing mice. Cancer Chemother Pharmacol. 1988;21: 117-121.

Presant CA, Coulter D, Valeriote F, Vietti TJ. Contrasting cytotoxicity kinetics of 5-azacytidine and dihydro-5-azacytidine hydrochloride in L1210 leukemia in mice. J Natl Cancer Inst. 1981;66: 11511154.

Qiang W, Jin T, Yang Q, Liu W, Liu S, Ji M, et al. PRIMA-1 selectively induces global DNA demethylation in p53 mutant-type thyroid cancer cells. J Biomed Nanotechnol. 2014; 10(7): 12491258.

Raffoux E, Cras A, Recher C, Boëlle PY, de Labarthe A, Turlure $\mathrm{P}$, et al. Phase 2 clinical trial of 5azacitidine, valproic acid, and all-trans retinoic acid in patients with high-risk acute myeloid leukemia or myelodysplastic syndrome. Oncotarget. 2010;1: 3442.

Raha P, Thomas S, Munster PN. Epigenetic modulation: a novel therapeutic target for overcoming hormonal therapy resistance. Epigenomics. 2011; 3: 451-470.

Riggs MG, Whittaker RG, Neumann JR, Ingram VM. n-butyrate causes histone modification in HeLa and Friend erythroleukaemia cells. Nature. 1977; 268: 462-464.

Juergens RA, Wrangle J, Vendetti FP, Murphy SC, Zhao M, Coleman B. Combination epigenetic therapy has efficacy in patients with refractory advanced nonsmall cell lung cancer. Cancer Discov. 2011;1: 598607.

Ruijter AJ, Gennip AH, Caron HN, Kemp S, Kuilenburg AB. Histone deacetylases (HDACs): characterization of the classical HDAC family. Biochem. J. 2003; 370(3): 737-749.

Ryan QC, Headlee D, Acharya M, Sparreboom A, Trepel JB, Ye J, et al. (2005). Phase I and pharmacokinetic study of MS-275, a histone deacetylase inhibitor, in patients with advanced and refractory solid tumors or lymphoma. J Clin Oncol. 2005; 23(17): 3912-3922.
Salz T, Deng C, Pampo C, Siemann D, Qiu Y, Brown $\mathrm{K}$, et al. Histone methyltransferase hSETD1A is a Novel Regulator of Metastasis in Breast Cancer. Mol Cancer Res. 2014;molcanres-0389.

Santo L, Hideshima T, Kung AL, Tseng JC, Tamang $\mathrm{D}$, Yang $\mathrm{M}$, et al. Preclinical activity, pharmacodynamic, and pharmacokinetic properties of a selective HDAC6 inhibitor, ACY-1215, in combination with bortezomib in multiple myeloma. Blood. 2012; 119(11): 2579-2589.

Schulte JH, Lim S, Schramm A, Friedrichs N, Koster $\mathrm{J}$, Versteeg R, et al. Lysine-specific demethylase 1 is strongly expressed in poorly differentiated neuroblastoma: implications for therapy. Cancer Res. 2009;69: 2065-2071.

Sehgal AR, Gimotty PA, Zhao J, Hsu JM, Daber R, Morrissette JD, et al. DNMT3A mutational status affects the results of dose-escalated induction therapy in acute myelogenous leukemia. Clin Cancer Res. 2015; 21(7): 1614-1620.

Seidel C, Florean C, Schnekenburger M, Dicato M, Diederich M. Chromatin-modifying agents in anticancer therapy. Biochimie. 2012; 94: 2264-2279.

Seligson, DB, HorvathS, Shi T, Yu H, Tze S, Grunstein $\mathrm{M}$, et al. Global histone modification patterns predict risk of prostate cancer recurrence. Nature. 2005; 435: 1262-1266.

Shen L, Cui J, Liang S, Pang Y, Liu P. Update of research on the role of EZH2 in cancer progression. Onco Targets Ther. 2013;6: 321-324.

Strickler JH, Starodub AN, Jia J, Meadows KL, Nixon $\mathrm{AB}$, Dellinger A, et al. Phase I study of bevacizumab, everolimus, and panobinostat (LBH-589) in advanced solid tumors. Cancer Chemother Pharmacol. 2012; 70(2): 251-258.

Sung JJ, Karagiannis TC. Combination Therapy for Cancer: Phototherapy and HDAC Inhibition. Molecular Mechanisms and Physiology of Disease. 2014: 445-470.

Suzuki M.M, Bird A. DNA methylation landscapes: provocative insights from epigenomics. Nat Rev Genet. 2008;9: 465-476.

Tahiliani M, Koh KP, Shen Y, Pastor WA, Bandukwala $\mathrm{H}$, et al. Conversion of 5-methylcytosine to 5hydroxymethylcytosine in mammalian DNA by MLL partner TET1. Science. 2009;324: 930-935.

Tan J, Cang S, Ma Y, Petrillo RL, Liu D. Novel histone deacetylase inhibitors in clinical trials as anti-cancer agents. J Hematol Oncol. 2010;3: 1-13.

Tan J, Yang X, Zhuang L, Jiang X, Chen W, Lee PL, et al. Pharmacologic disruption of Polycomb-repressive complex 2-mediated gene repression selectively induces apoptosis in cancer cells. Genes Dev. 2007; 21: 1050-1063

Thakur VS, Gupta K, Gupta S. Green tea polyphenols causes cell cycle arrest and apoptosis in prostate cancer cells by suppressing class I histone deacetylases. Carcinogenesis. 2012;33: 377-84. 
Waddington C.H. The epigenotype. Endeavour. 1942; 1: $18-20$.

Wang H, Cao Q, Dudek AZ. Phase II study of panobinostat and bortezomib in patients with pancreatic cancer progressing on gemcitabine-based therapy. Anticancer Res. 2012; 32: 1027-1031.

Wang H, Lee S, Nigro CL, Lattanzio L, Merlano M, Monteverde M, et al. NT5E (CD73) is epigenetically regulated in malignant melanoma and associated with metastatic site specificity. $\mathrm{Br} J$ Cancer. 2012; 106: 1446-1452.

Wang J, Hevi S, Kurash JK, Lei H, Gay F, Bajko J, et al. The lysine demethylase LSD1 (KDM1) is required for maintenance of global DNA methylation. Nat Genet. 2009; 41: 125-129.

Wang J, Lu F, Ren Q, Sun H, Xu Z, Lan R, et al. Novel Histone Demethylase LSD1 Inhibitors Selectively Target Cancer Cells with Pluripotent Stem Cell Properties. Cancer Res. 2011: 7238-7249.

Wang S, Chen R, Zhong Z, Shi Z, Chen M, Wang Y. Epigallocatechin-3-Gallate Potentiates the Effect of Curcumin in Inducing Growth Inhibition and Apoptosis of Resistant Breast Cancer Cells. Am J Chin Med. 2014; 42(05): 1279-1300.

Watt PM, Kumar R, Kees UR. Promoter demethylation accompanies reactivation of the HOX11 protooncogene in leukemia. Genes Chromosom Cancer. 2000; 29: 371-377.

Witta SE, Jotte RM, Konduri K, Neubauer MA, Spira AI, Ruxer RL, et al. Randomized phase II trial of erlotinib with and without entinostat in patients with advanced non-small-cell lung cancer who progressed on prior chemotherapy. J Clin Oncol. 2012;30: 22482255.

Wu Y, He L, Zhang L, Chen J, Yi Z, Zhang J, et al. Anacardic Acid (6-Pentadecylsalicylic Acid) Inhibits Tumor Angiogenesis by Targeting Src/FAK/Rho GTPases Signaling Pathway. J Pharmacol Exp Ther. 2011; 339: 403-441.
Xiong H, Du W, Zhang YJ, Hong J, Su WY, Tang JT, Wang YC, Lu R, Fang JY. Trichostatin A, a histone deacetylase inhibitor, suppresses JAK2/STAT3 signaling via inducing the promoterassociated histone acetylation of SOCS1 and SOCS3 in human colorectal cancer cells. Mol Carcinog. 2012; 51(2):174-184.

Yang Q, Wang B, Zang W, Wang X, Liu Z, Li W, et al. Resveratrol inhibits the growth of gastric cancer by inducing G1 phase arrest and senescence in a Sirt1dependent manner. PLoS ONE. 2013; 8(11):e70627.

Younes A, Sureda A, Ben-Yehuda D, Zinzani PL, Ong TC, Prince HM, et al. Panobinostat in patients with relapsed/refractory Hodgkin's lymphoma after autologous stem-cell transplantation: results of a phase II study. J Clin Oncol. 2012;30: 2197-2203.

Zhan Y, Chen Y, Liu R, Zhang H, Zhang Y. Potentiation of paclitaxel activity by curcumin in human breast cancer cell by modulating apoptosis and inhibiting EGFR signaling. Arch Pharm Res. 2014; 37(8): 1086-1095.

Zhang Q, Helfand B, Lin X, Jang T, Guo Y, Khandekar $\mathrm{J}$, et al. Human prostate cancer invasion could be suppressed by 5-Aza-2'-deoxycytidine which can inhibit the TGF- $\beta$ induced DNA methyltransferase (DNMT). Cancer Res. 2014; 74(19): 4038.

Zhao Q, Fan J, Hong W, Li L, Wu M. Inhibition of cancer cell proliferation by 5-fluoro-2'-deoxycytidine, a DNA methylation inhibitor, through activation of DNA damage response pathway. Springerplus. 2012; 1: 65 .

Zhou J, Bi C, Cheong LL, Mahara S, Liu SC, Tay KG, et al. The histone methyltransferase inhibitor, DZNep, up-regulates TXNIP, increases ROS production, and targets leukemia cells in AML. Blood. 2011; 118: 2830-39.

Zhu X, He F, Zeng H, Ling S, Chen A, Wang Y, et al. Identification of functional cooperative mutations of SETD2 in human acute leukemia. Nat Genet. 2014; 46(3): 287-293. 